$$
\begin{aligned}
& \text { مدلسازى يراكنش و ارتباط رويشَاهى كَ تَندم خوئى در شمال غرب ايران }
\end{aligned}
$$

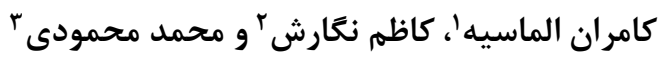

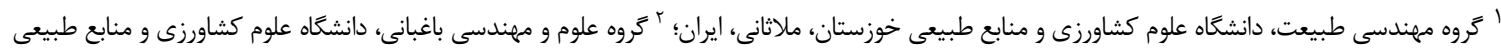

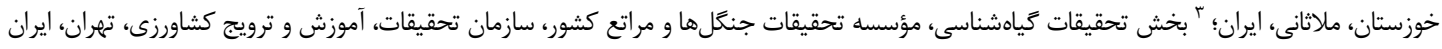

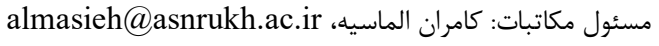

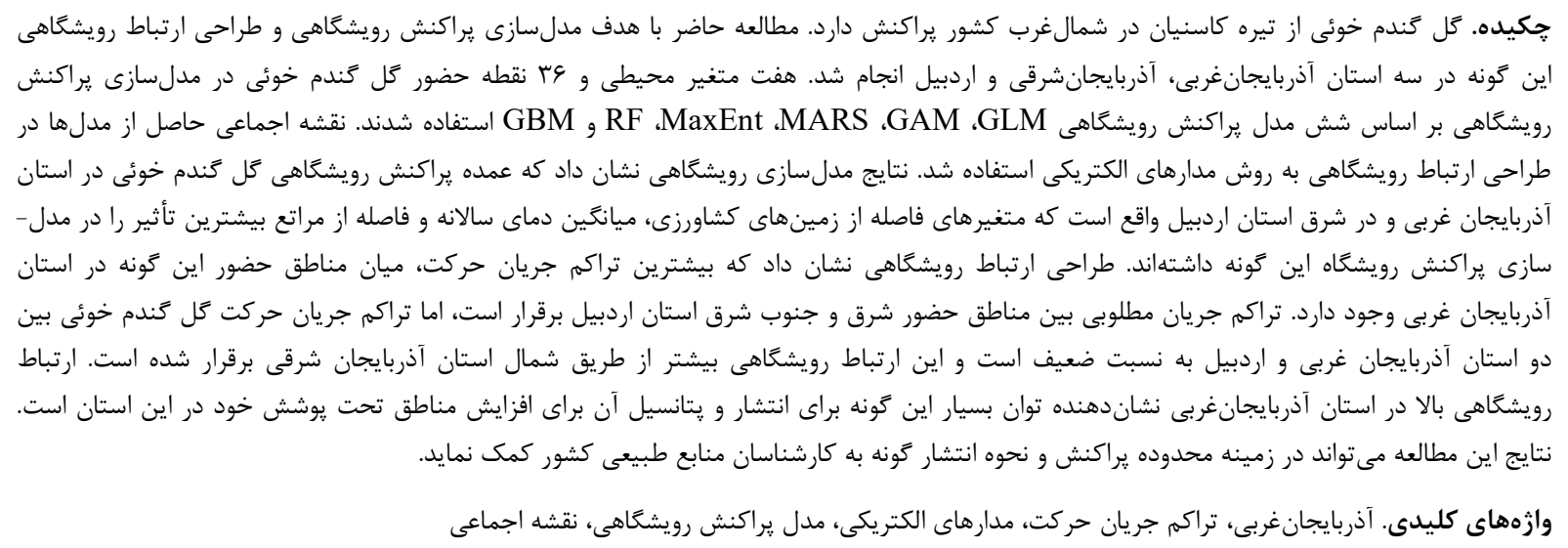

\title{
Habitat distribution and connectivity modelling of Centaurea glastifolia in Northwest of Iran
}

\author{
Kamran Almasieh ${ }^{1}$, Kazem Negaresh ${ }^{2}$ \& Mohammad Mahmoodi ${ }^{3}$ \\ ${ }^{1}$ Department of Nature Engineering, Agricultural Sciences and Natural Resources University of Khuzestan, Mollasani, \\ Iran ${ }^{2}$ Department of Horticulture, Agricultural Sciences and Natural Resources University of Khuzestan, Mollasani, \\ Iran, ${ }^{3}$ Botany Research Division, Research Institute of Forests and Rangelands, Agricultural Research, Education and \\ Extension Organization (AREEO), Tehran, Iran \\ Correspondent author: Kamran Almasieh, almasieh@asnrukh.ac.ir
}

\begin{abstract}
Centaurea glastifolia, a plant species from the Asteraceae family, is distributed in the Northwest of Iran. This study carried out to determine suitable habitats and habitat connectivity of Centaurea glastifolia in three Provinces of West Azarbayejan, East Azarbayejan and Ardabil. Seven habitat variables and 36 presence points were selected for habitat modelling using six habitat distribution models of GLM, GAM, MARS, MaxEnt, RF and GBM. The ensemble map resulting from these models was used for habitat connectivity modelling using electrical-circuit method. Results of habitat evaluation revealed that suitable habitats of the species studied were mainly located in West Azarbayejan and east of Ardabil Provinces, for which distance from agricultural lands, mean annual temperature and distance from rangelands had the highest contribution to the model. Habitat connectivity modelling showed that the current density movement was highest in West Azarbayejan. Current density movement between East and Southeast of Ardabil was evaluated to be significant, whereas the current density movement between West Azarbayejan and Ardabil Provinces was relatively low. The high current density movement in West Azarbayejan indicates the species' high dispersal ability in expanding its range across the area. The results of the current study could facilitate understanding of the distribution and dispersal of Centaurea glastifolia.
\end{abstract}

Key words. current density movement, electrical circuit, ensemble map, habitat distribution model, West Azarbayejan

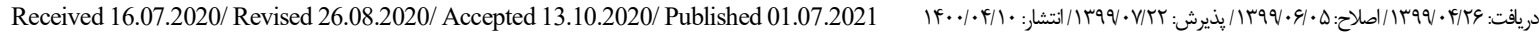


مطالعه دشوار مىسـازند (Pearson et al., 2006). بنـابراين، در

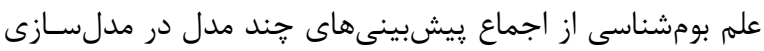

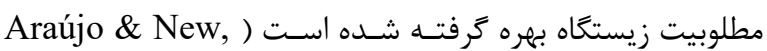

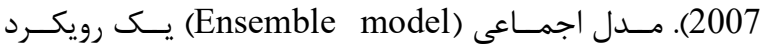
قدرتمند است كه با تركيب مدل هاى مختلف صحت مـدل را بـالا

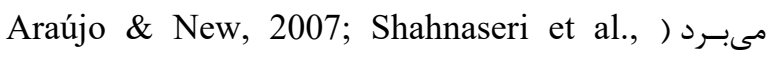
2019). در اين ميان، بسته (Thuiller et al., 2009) Biomod در نرمافزار R از اين رويكرد اسـتفاده كـرده اسـت و بـا محاسـبه

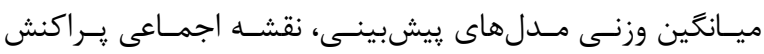
رويشكاهى را تهيه مى كند (Thuiller et al., 2009).

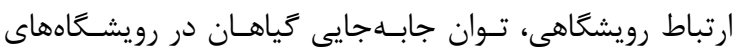

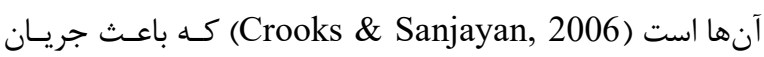

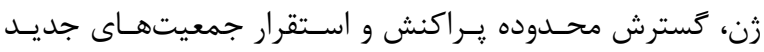

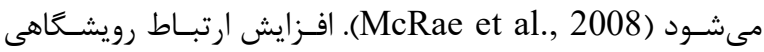

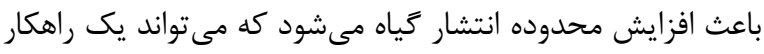

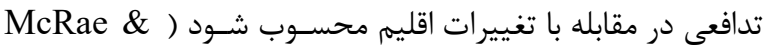

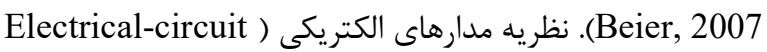

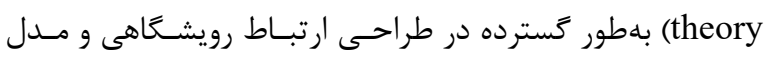

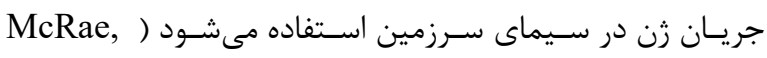

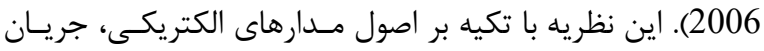

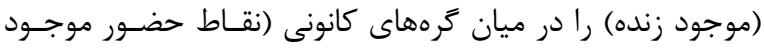

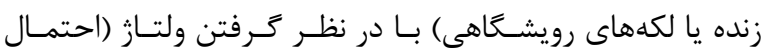
حركت موجود زنده) و مقاومت (نفوذيذيرى رويشكاه) پيشبينسى

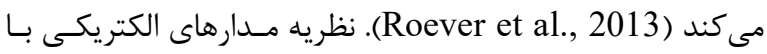
شناسايى مسيرهاى مختلف ارتباط ميان نقاط حضـور نسـبت بـهـ نظريه حداقل هزينه كه فقط يك مسير ارتباط را معرفى مى كند،

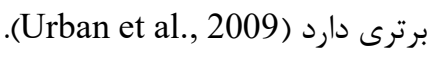
تيره كاسنيان (Asteraceae) بزركترين تيره از كياهان كلدار

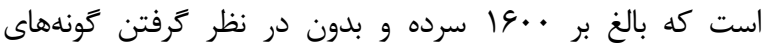

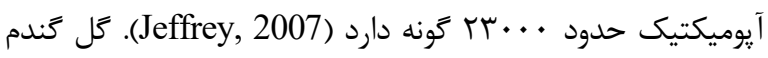
يكى از بزرگترين سردهاى اين تيره است و (Centaurea L.)

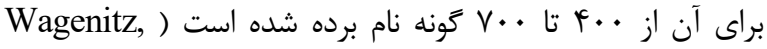
سرد سرده در ايران شامل تا حدود • ل ال گونه است كه در تمامى نقاط

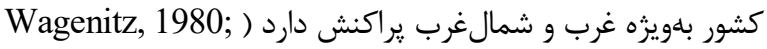
(Ghahremaninejad et al., 2012; Negaresh, 2019 تعداد حدود • له كَنه انحصارى ايران هستند. يكى از گَونههاى اين

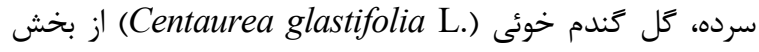
Chartolepis (Cass.) DC.

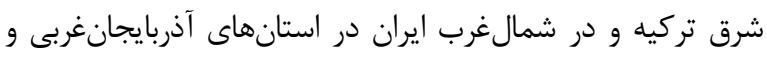

مقلهـ

مدلهاى براكنش رويشَاهى ( Habitat Distribution Models, مدمه

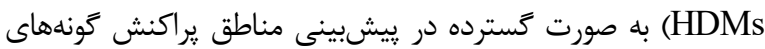
كياهى و جانورى كاربرد دارند ) Guisan \& Zimmermann, 2000 Alignier et al., 2013; Ghaedi et al., 2020 بامنظور درك عوامل موثر بر يراكنش گونه، همبستكى بين متغيرهاى

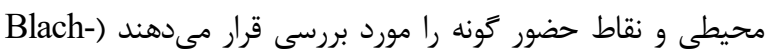
م Overgaard et al., 2010 مى كنند (Araújo \& Peterson, 2012). براى دستيابى به مدل يراكنش موفق كونه، انتخاب نوع مدل اهميت خاصى دارد ( Araújo .(\& Guisan, 2006

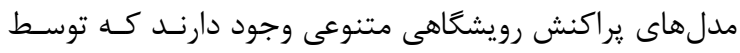

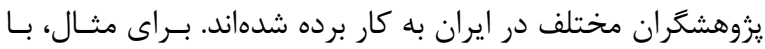
استفاده از روش تحليل فاكتور آشيان بومشناختى ( Ecological (Niche Factor Analysis, ENFA درمنه كـوهى (Artemisia aucheri Boiss. در مراتع اسـتان مازندران (Borna et al., 2020) و جند تيب يوشش در جنسوب

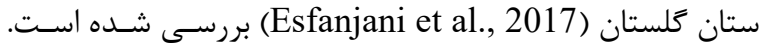

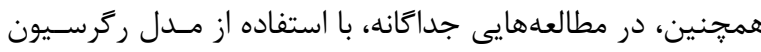

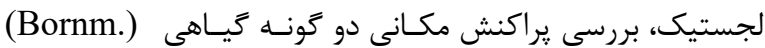
(Gouan) Parl. gLimonium iranicum Lincz.

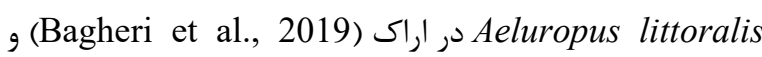

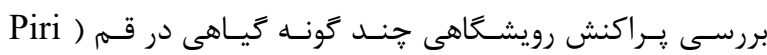
(Sahragard et al., 2016

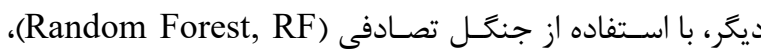

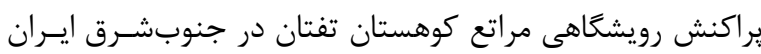

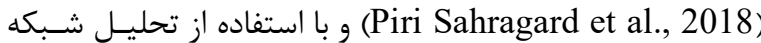
مصـنوعى (Artificial Neural Network, ANN)، رويشـاه

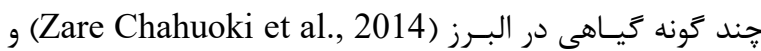
يراكنش كونه .Seidlitzia rosmarinus Bunge ex Boiss در كياهي در البرز

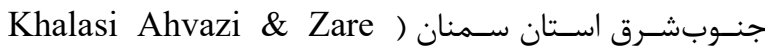
(Chahuoki, 2016

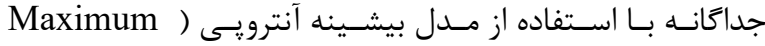
Desf. Entropy, MaxEnt Zare Chahuoki et ( در حوزه آبخيز طالقـان Stipa barbata Rheum ribes L. (al., 2018

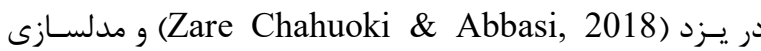

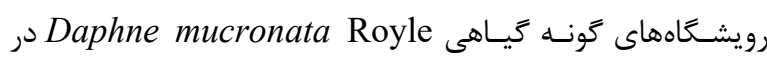

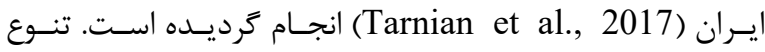

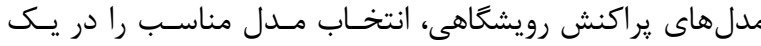


Melilotus officinalis (L.) Pall. و Plantago lanceolata L.

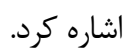

آكاهى در مورد براكنش رويشَاهى كَّنه كَ كل كندم خوئي و

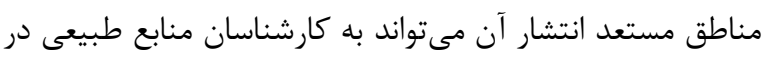

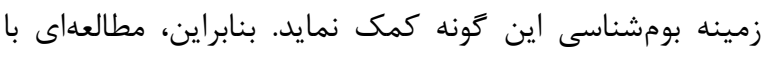

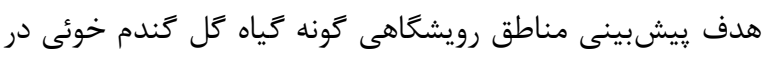

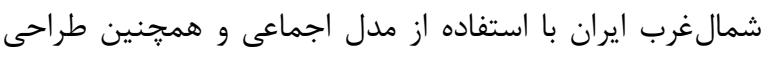

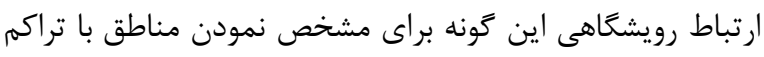

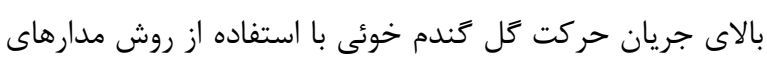

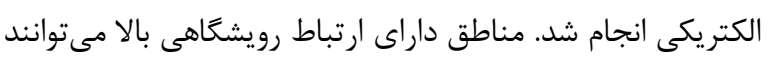
نواحى انتشار اين گونه محسوب شوند.

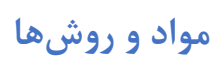

مشخصات منطقه مورد مطالعه

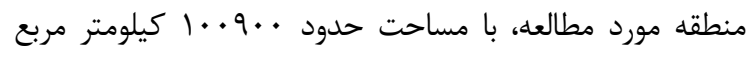

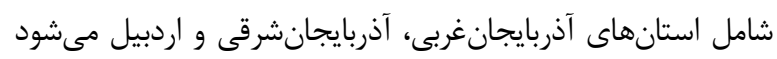

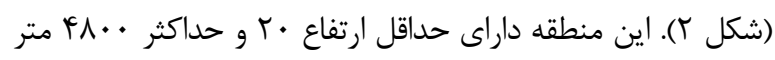

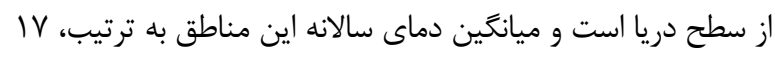

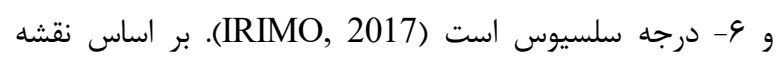

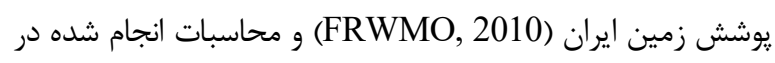

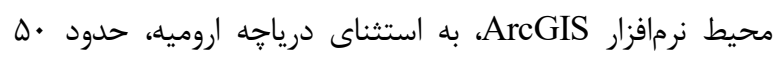

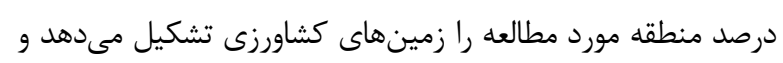

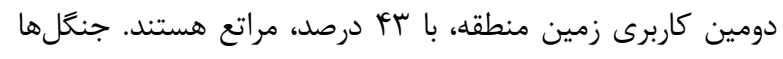

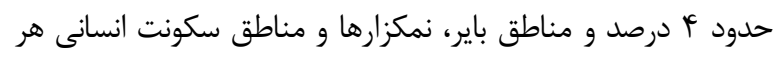

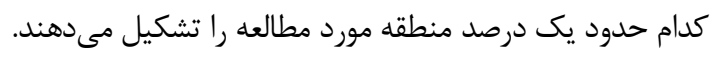

اردبيل يراكنش دارد (Wagenitz, 1980). اين كياه در شرق تركيه

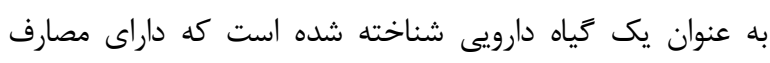

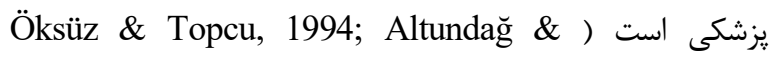

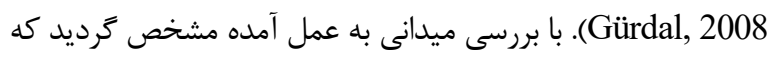

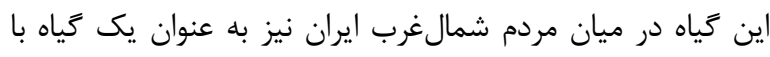

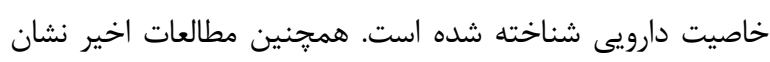

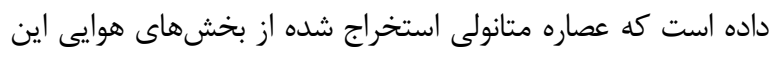

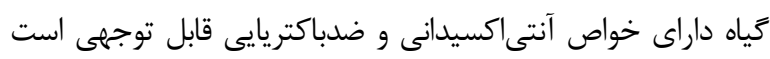

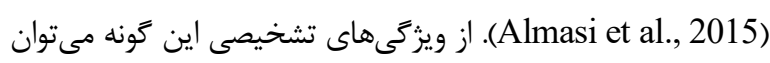

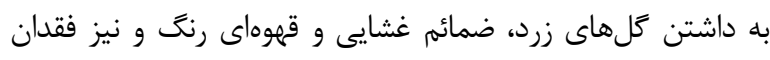

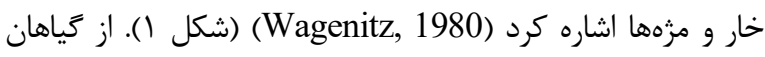

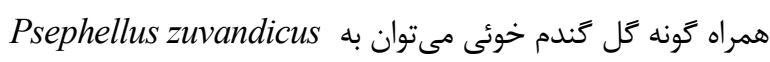
Arctium platylepis (Boiss. \& Bal.) Sosn. ex ،Sosn. Cerinthe minor Symphytum asperum Lepech. ‘Grossh. Cirsium congestum L. ،Cirsium arvense (L.) Scop. ،L. Cirsium echinus (M.Beib.) Hand.- ،var. congestum Carduus ،Carduus onopordioides Fisch. ex M.B. Mzt. ،hamolusus Ehrh. subsp. hystrix (C.A.Mey.) Kazmi Tanacetum polycephalum Sch.-Bip. subsp. ¿Poa bulbosa L. argyrophyllum (C.Koch) Podl. Stachys byzantina C.Koch Bromus tomentollus Boiss. Salvia xanthocheila Boiss. ex stachys pubescens Ten. Lamium album L. SSalvia limbata C.A.Mey. ،Benth. Lolium perenne ،Medicago lupulina L. ،subsp. album ،Onopordum leptolepis DC. ،Cichorium intybus L. ‘L.

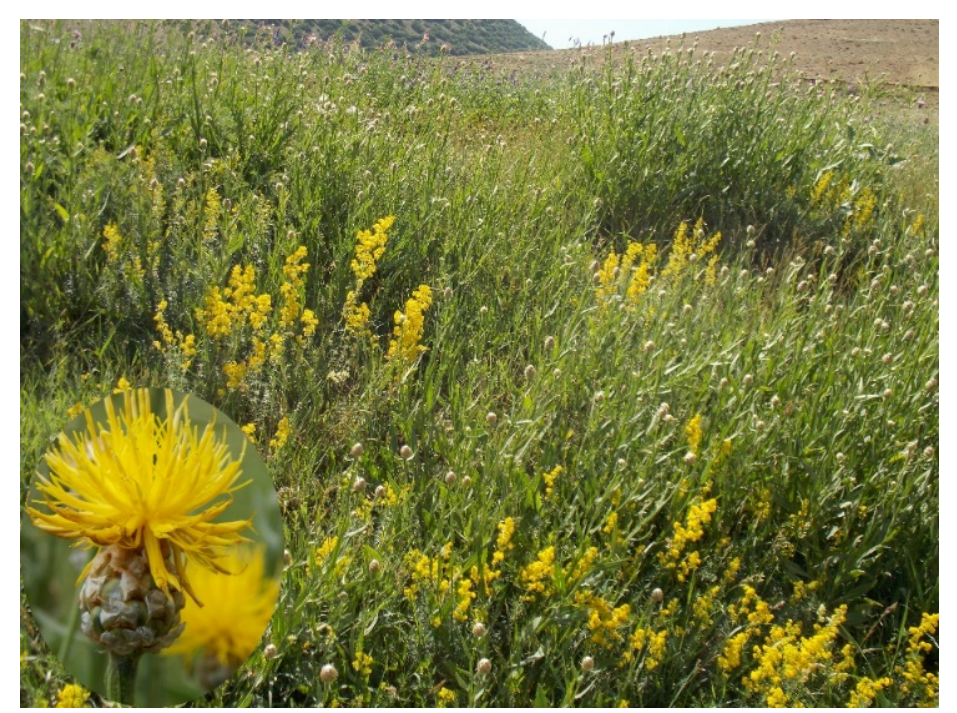

شكل ا- كَنه كَ گَندم خوئى در اطراف شهر خلخال در استان اردبيل و رويشخاه طبيعى آن (تصوير از كاظم نحارش).

Figure 1. Centaurea glastifolia around Khalkhal city from Ardabil Province and its natural habitat (Photo by Kazem Negaresh). 


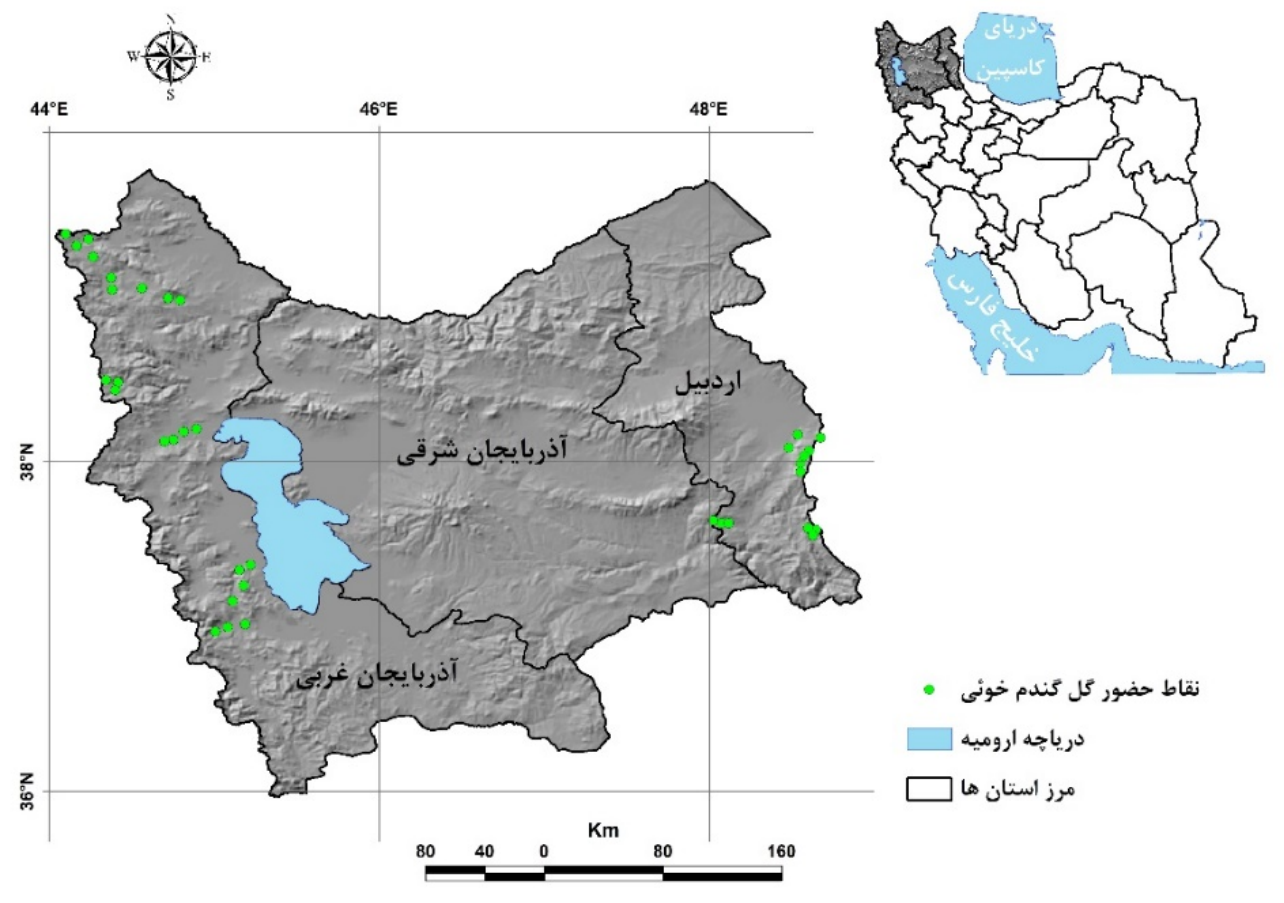

شكل r - منطقه مورد مطالعه (استانهاى آذربايجان غربى، آذربايجان شرقى و اردبيل) به همراه نقاط حضور كونه كل كندم خوئى.

Figure 2. Study area (West Azarbayejan, East Azarbayejan and Ardabil provinces) with the presence points of Centaurea glastifolia.

انتشار زونهها در مناطق دشـتى نسـبت بـه منـاطق كوهسـتانى) براى حذف نقاط حضور نزديك به هم استفاده شد. براى اين كـار از دسـتور Spatially Rarify Occurrence Data در نرمافـزار SDMtoolbox استفاده شد (Brown, 2014). در نهايت، تعداد

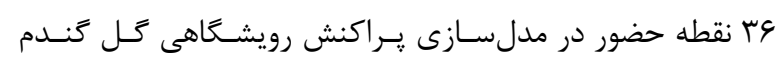

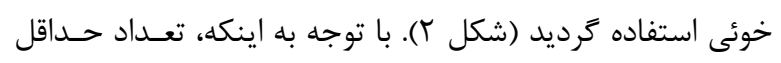

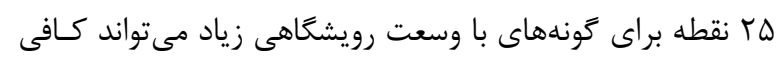

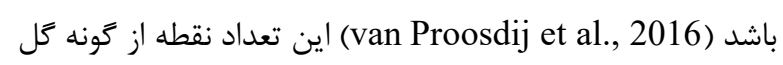
كندم خوئى مىتواند در مدلسازى ڤيراكنش رويشگاهى آن كفـاف

دهد.

\section{متغير هاى محيطى دهي}

انتخاب متغيرهاى محيطى نبايد صرفا مربـوط بــهـ يـك قلمــرو

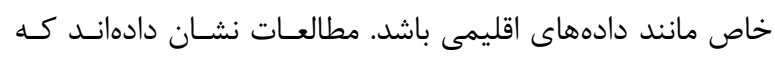

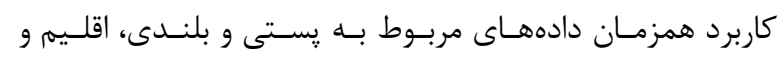

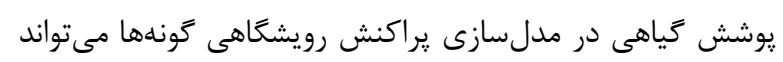

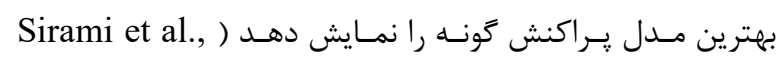

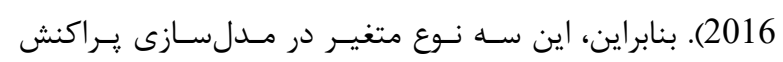

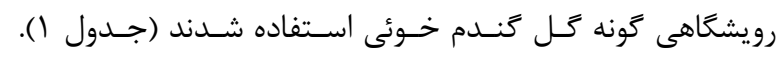
متغير مدل رقومى ارتفاع با اندازه سلول يك كيلومتر بهعنوان يكى رونى

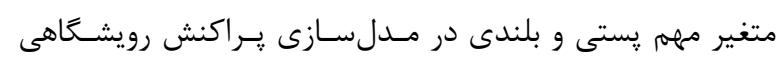

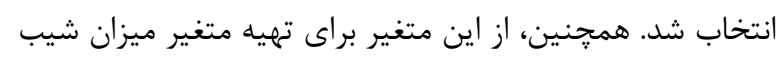

گرد آورى نقاط حضور

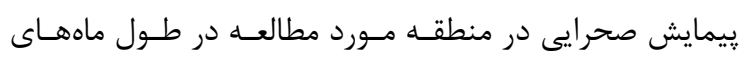

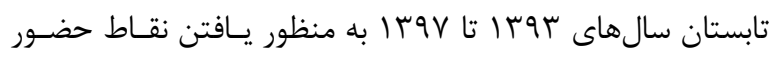
كل عَندم خوئى انجام شد. از فلور ايرانيكـا (Wagenitz, 1980)

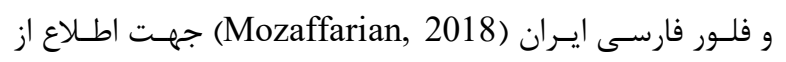
محدوده و مناطق يراكنش گونه استفاده شد. علاوهبر مناطق ذكــر

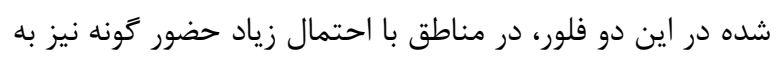

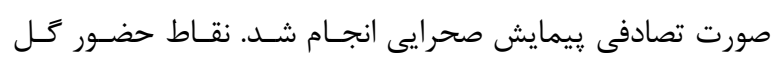
كنـدم خــوئى توسـط دسـتخاه موقعيتيـاب جهـانى ( Global (Positioning System, GPS شد. با توجه به اينكه فصل تابستان زمان بلوغ و كلدهى اين گونه

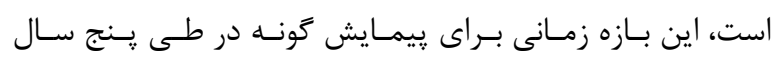

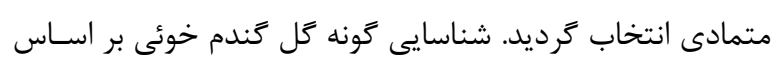
خصوصيات برى، گل و ميوه بر اساس فلور ايرانيكا صورت كرفت.

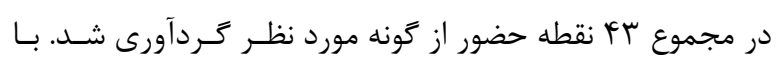

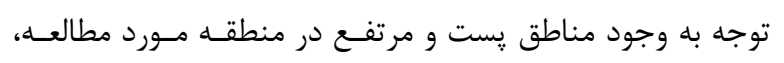
نقشه ناهمگًونى مكانى (Spatial heterogeneity map) منطقه با مابزار Focal Statistic و از نقشه مدل رقومى ارتفاع ( Digital Elevation Model, DEM

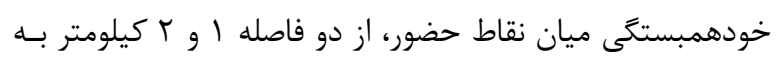

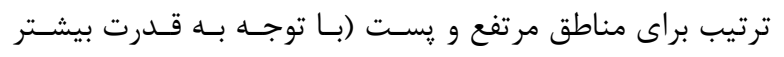


Generalized Additive Model, ) افزوده تعميم يافته Multivariate ) و ركرسيون جند متغيره تطبيقى ) (GAM ميني

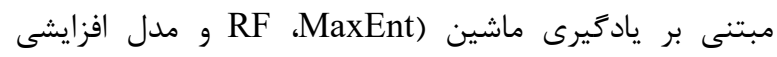

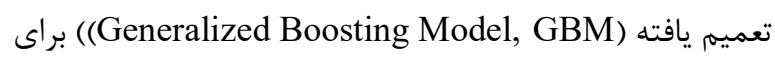

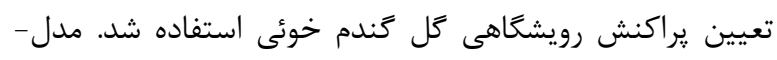

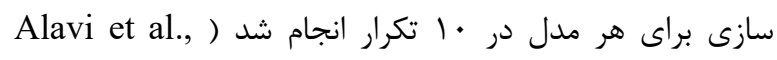

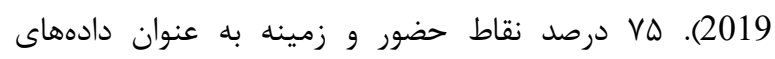

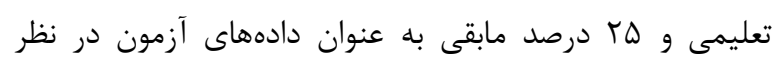

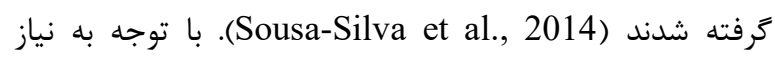
مدلهاى ذكر شده به دادههاى زمينهاى (فقدان دروغين)، تعداد

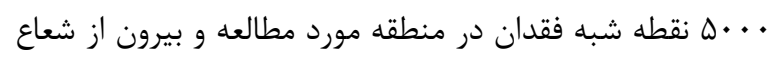
دو كيلومترى نقاط حضور بلهصورت تصادفى در نظر كرفته شد.

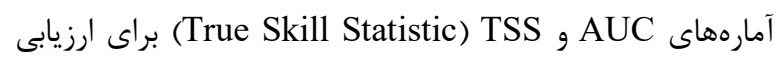
اعتبار و كيفيت هر يك از مدلها و مدل اجماعى استفاده شد. بـ إنه

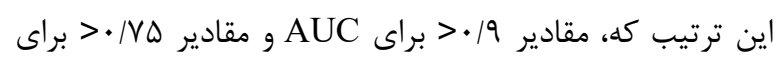

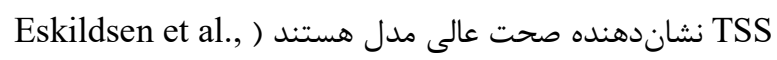

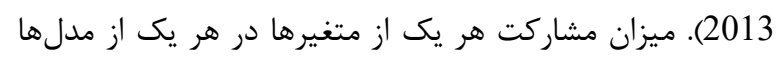

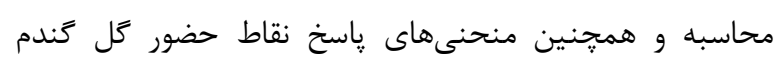

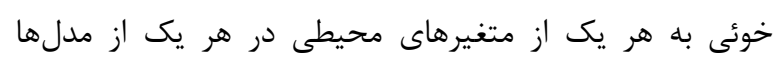

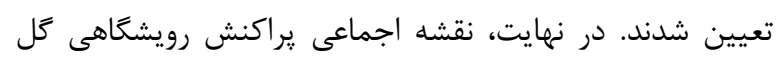

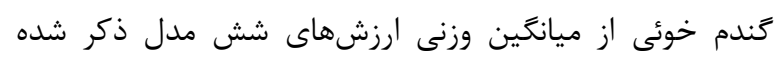

تهيه كرديد (Thuiller et al., 2009).

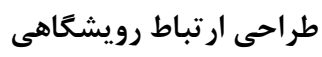

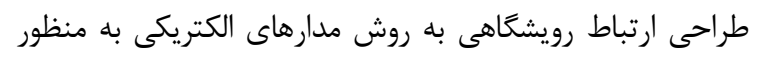

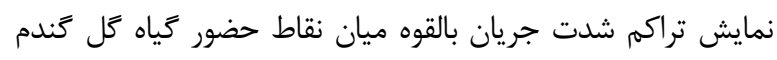

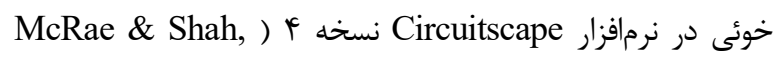

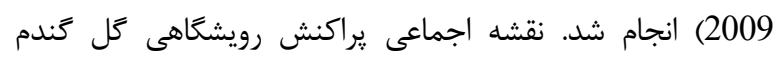

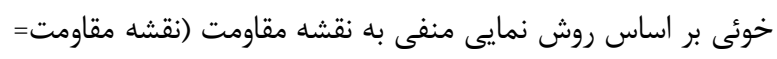

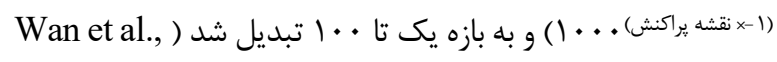

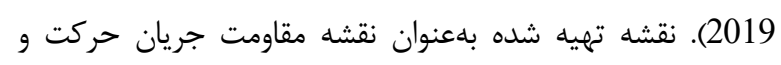

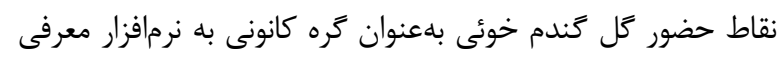

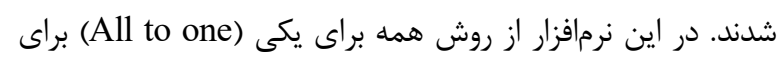

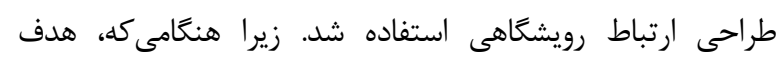

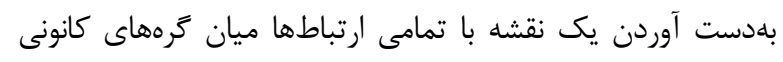
است اين روش مىتواند مفيد واقع شود (McRae et al., 2008).

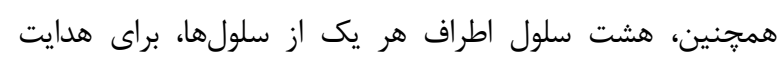

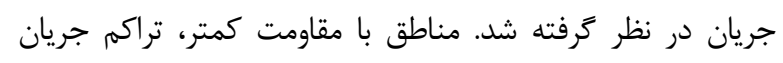

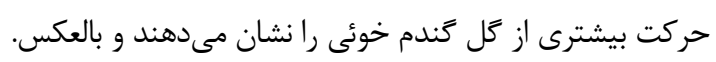

و متغير سختى (Roughness ،انحـراف معيـار نقشـه ارتفـاع) در

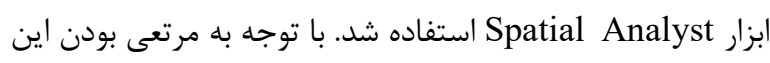

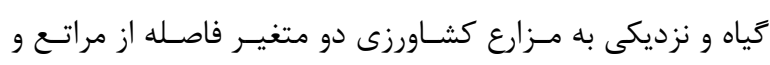

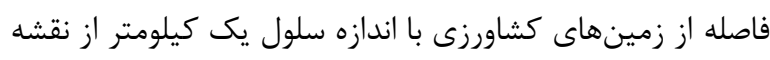

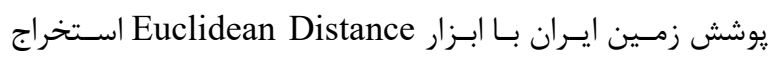

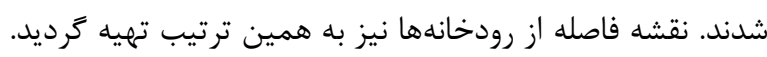

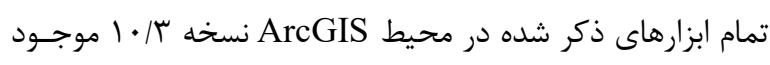

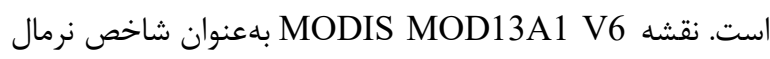

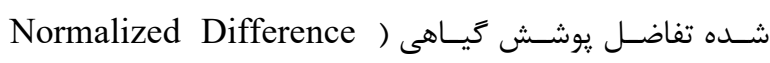
(Vegetation Index, NDVI http://earthexplorer.usgs.gov

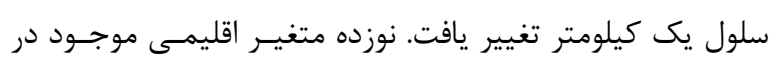

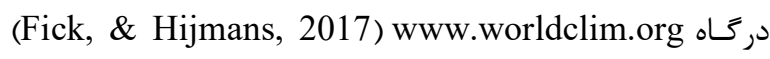
بادليل تأثير دما و رطوبت بر يراكنش، فيزيولـوزى و مورفولـوزى (

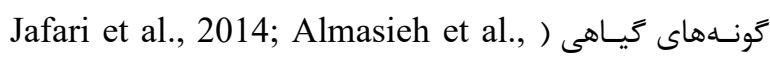

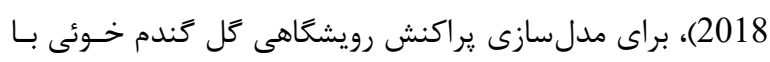

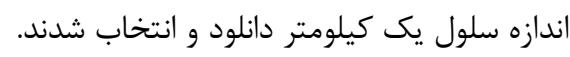

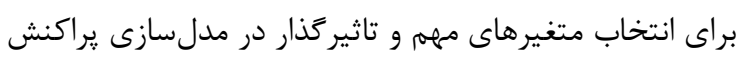

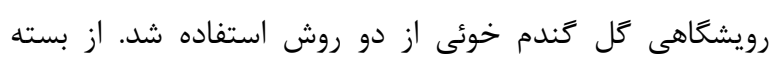
در (Jueterbock, 2015) MaxentVariableSelection محيط نرمافزار Rيزان مشاركت بالاتر از يك درصد، افزايش- مهن

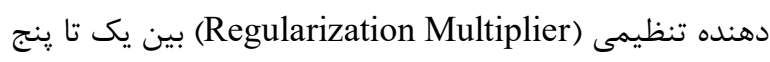

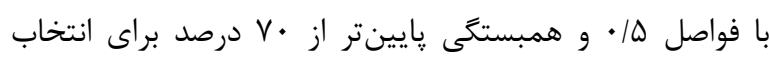

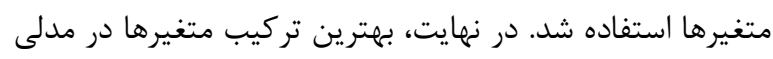

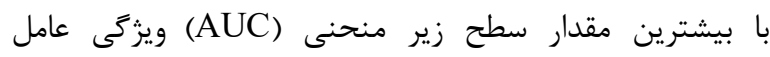

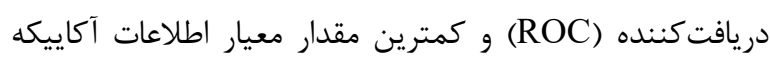

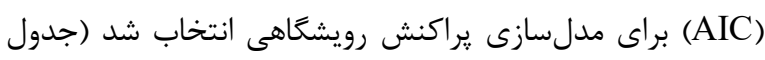

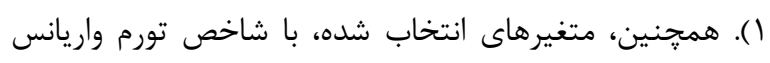

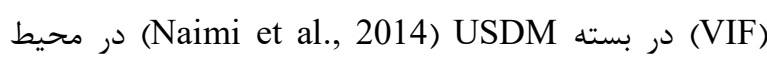
نرمافزار R و آستانه VIF بزر كتر از عدد سه براى حذف متغيرها بر برسى شدند (Zuur et al., 2010).

$$
\text { مدلسازى براكنش رويشعاهى ندئ }
$$

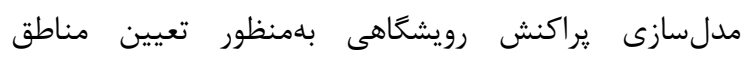

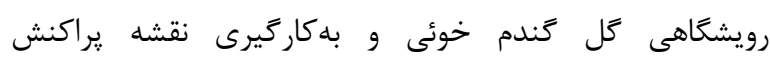

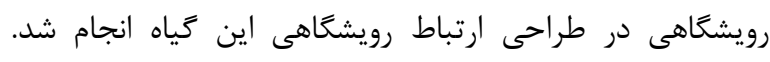

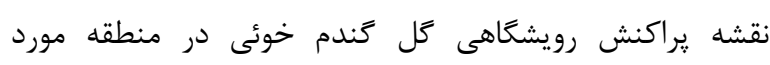
مطالعه با استفاده از بسته Biomod2 در محيط محيط نرمافزار آمارى

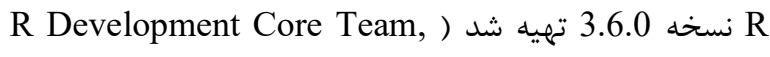

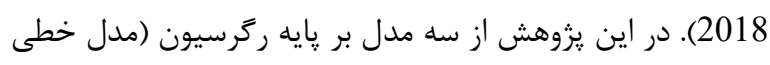

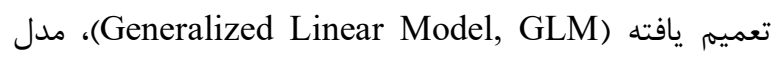


جدول ا- متغيرهاى محيطى منتخب و نهايى در مدلسازى يراكنش رويشَاهى گل گَندم خوئى در منطقه مورد مطالعه.

Table 1. Chosen and final environmental variables for habitat distribution modelling of Centaurea glastifolia in the study area.

\begin{tabular}{|c|c|c|c|}
\hline VIF مقدار & $\begin{array}{l}\text { متغير نهايى بر اساس بيشترين AUC } \text { ومترين AIC } \\
\text { AIC }\end{array}$ & نام متغير منتخب & 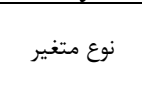 \\
\hline & & ارتفاع & يستى و بلندى \\
\hline \multirow[t]{2}{*}{$1 / \pi \Lambda$} & * & ميزان شيب & \\
\hline & & سختى & \\
\hline $1 / 11$ & * & فاصله از مراتع & يوشش و آب \\
\hline $1 / T r$ & $*$ & فاصله از زمينهاى كشاورزى & \\
\hline $1 / \cdot 0$ & * & NDVI & \\
\hline $1 / 11$ & * & فاصله از رودخانهها & \\
\hline \multirow[t]{11}{*}{$1 / \pi r$} & * & ميانكَين دماى سالانه (BIO1) & اقليمى \\
\hline & & بازه ميانكَين روزانه دما (BIO2) & \\
\hline & & ايزوترماليتى (BIO3) & \\
\hline & & تنوع فصلى دما (BIO4) & \\
\hline & & بالاترين دماى كرمترين ماه سال (BIO5) & \\
\hline & & پايينترين دماى سردترين ماه سال (BIO6) & \\
\hline & & بازه سالانه دما (BIO7) & \\
\hline & & ميانكَين دماى مرطوبترين هارى (BIO8) & \\
\hline & & ميانكَين دماى خشكترين جارى (BIO9) & \\
\hline & & ميانكين دماى كرمترين جارى (BIO10) & \\
\hline & & ميانكين دماى سردترين خارك (BIO11) & \\
\hline \multirow[t]{8}{*}{$1 / \pi r$} & * & بارندَى سالانه (BIO12) & \\
\hline & & بارندگى مرطوبترين ماه (BIO13) & \\
\hline & & بارندگى خشكترين ماه (BIO14) & \\
\hline & & تنوع فصلى بارندگى (BIO15) & \\
\hline & & بارندگى مرطوبترين خارى (BIO16) & \\
\hline & & بارندَى خشكترين خارى (BIO17) & \\
\hline & & بارندگى كرمترين جارك (BIO18) & \\
\hline & & بارندكى سردترين جارك (BIO19) & \\
\hline
\end{tabular}

جدول r- مقادير AUC و TSS (كمترين، بيشترين، ميانگين و انحراف معيار) براى هر يك از مدلهاى استفاده شده در · ا تكرار و مدل اجماعى در مدلسازى يراكنش رويشگاهى كل گَندم خوئى در منطقه مورد مطالعه.

Table 2. AUC and TSS values (minimum, maximum, mean and standard deviation) for each model in 10 replication and ensemble model used in habitat distribution of Centaurea glastifolia in the study area.

\begin{tabular}{|c|c|c|c|c|c|c|c|c|}
\hline \multicolumn{4}{|c|}{ مقادير TSS } & \multicolumn{4}{|c|}{ AUC مقادير } & \multirow{2}{*}{ مدل } \\
\hline معيار & ميانكين & بيشترين & كمترين & انحراف معيار & ميانكين & بيشترين & كمترين & \\
\hline $.1 . \mathrm{FF}$ & $\cdot \mid \Lambda \& V$ &.$/ 910$ & $\cdot / A \cdot V$ & . &.$/ 941$ &.$/ 94 \wedge$ & $.19 \cdot 1$ & GLM \\
\hline $.1 \cdot T r$ & $\cdot / V \& \Delta$ & $\cdot / 1$ & . VMT &.$/ . r$ & $\cdot / 9 \cdot r$ & . 194 & $\cdot / 19$ & GAM \\
\hline . &.$/ 9 T 1$ &.$/ 9 \vee \Delta$ & $\cdot / \mathrm{AV}$ & $.1 \cdot 1 \mathrm{~V}$ &.$/ 981$ & . 1994 & . 1949 & MARS \\
\hline $.1 . r 9$ & $\cdot 19 \cdot \mathrm{r}$ & .190 & $\cdot / 19$ &.$/ \cdot 14$ &.$/ 9 G 4$ & . /qты & .1914 & MaxEnt \\
\hline r & $\cdot / 1 \cdot \Lambda$ & $\cdot / \Lambda \Delta$ & ./VG & .1 .99 &.$/ 994$ & .1949 &.$/ 9 V V$ & $\mathrm{RF}$ \\
\hline . & - IAFS & $\cdot / 9 \cdot \Delta$ & $\cdot|A|$ & $.1 \cdot T F$ & .194 & $\cdot / 9 \cdot 0$ &.$/ 9 \vee 9$ & GBM \\
\hline - & - INDT & - & - & - &.$/ 94 \Delta$ & - & - & مدل اجماعي \\
\hline
\end{tabular}


جدول r - ميانكَين و انحراف معيار مشاركت نسبى هر يك از متغيرهاى محيطى در شش مدل مورد استفاده در براكنش رويشكاهى كل كندم خوئى در منطقه مورد مطالعه.

Table 3. Relative contributions (mean and standard deviation) for each environmental variable used in habitat distribution of Centaurea glastifolia in the study area.

\begin{tabular}{|c|c|c|c|c|c|c|c|}
\hline 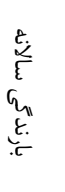 & 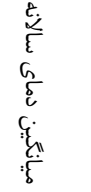 & 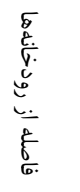 & $\underset{ડ}{Z}$ & 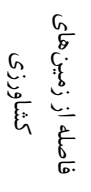 & $\frac{\frac{\tau_{i}}{\delta}}{\frac{\delta}{\sigma}}$ & 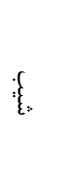 & \\
\hline N/VT & $19 / \cdot r$ & $1 \cdot / \mathrm{VK}$ & $11 / 11$ & TN/AV & 191.4 & F/VG & ميانكين مشاركت نسبى (.)) \\
\hline 1/90 & $1 / \cdot 1$ & $r / \mu 1$ & $r / \cdot \varphi$ & $Y / \cdot r$ & r/q & 1/9 & انحراف معيار مشاركت نسبى (./) \\
\hline
\end{tabular}

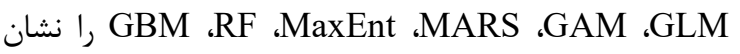

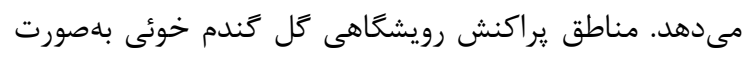

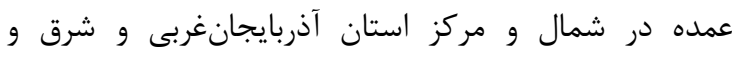

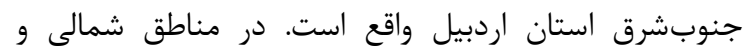

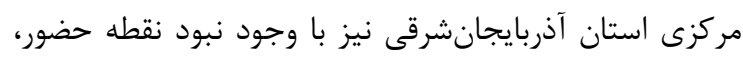

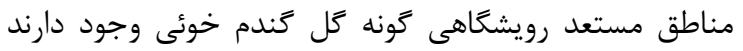

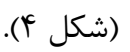

\section{طراحى ارتباط رويشَاهى}

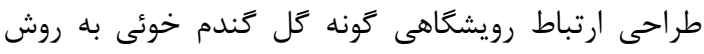

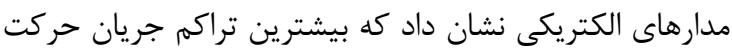

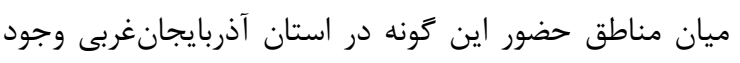

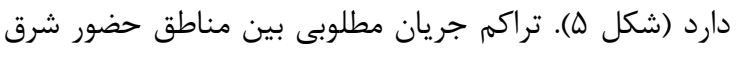

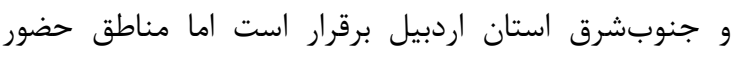

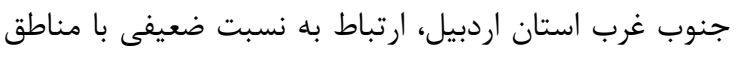

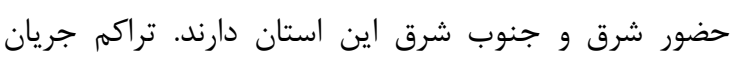

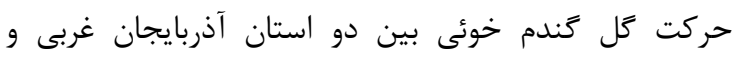

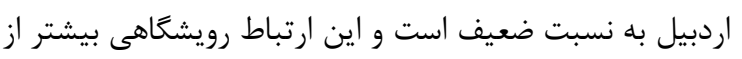

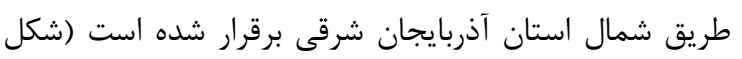

\section{بحث و نتبجه تيبرى}

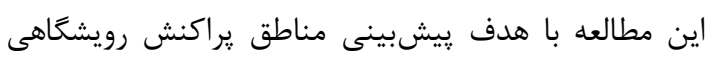

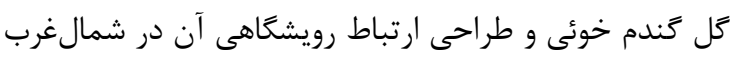

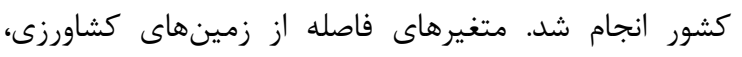

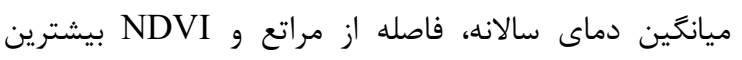

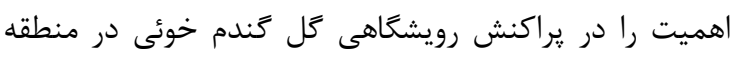

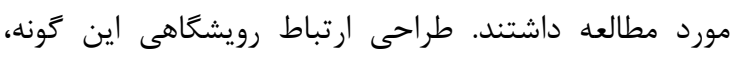

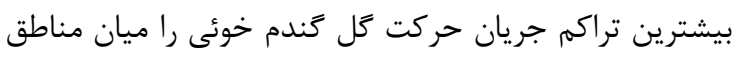
حضور استان آذربايجان غربى نشان داد حركت

\section{نتايج}

مدلسازى : ماركنش رويشگاهى

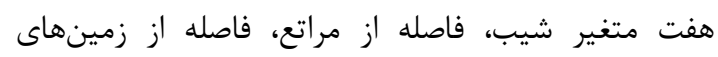
كشاورزى، NDVI، فاصله از رودخانهها، ميانگين دماى سالانه (BIO1) و بارندگى سالانه (BIO12) در مدلى با بيشترين مقدار AUC و كمترين مقدار AIC انتخاب شدند. مقدار VIF اين متغيرها نيز از عدد سه كمتر بود. بنابراين، همه آنها براى مدلسازى يراكنش رويشخاهى گل گَندم خوئى استفاده شدند (جدول ()). در مدلسازى يراكنش رويشخاهى، ميانگين مقدار

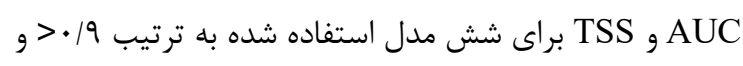

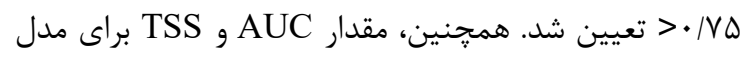

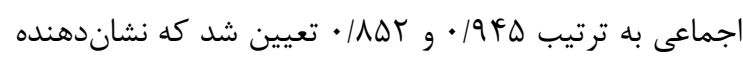
صحت عالى براى هر يك از مدلها و مدل اجلى اجماعى است

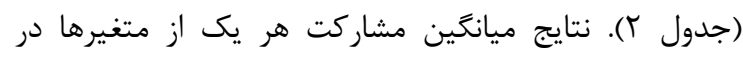
شش مدل تعيين :راكنش رويشگاه گونهاى نشان داد كه متغير

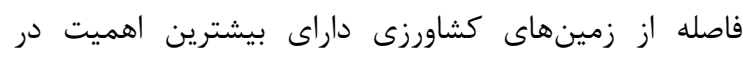
يراكنش رويشگاهى گل گَندم خوئى در منطقه مورد مطالعه است. بعد از آن به ترتيب، متغير ميانگين دماى سالانه، فاصله

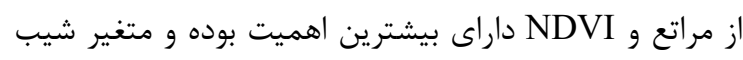

$$
\text { داراى كمترين اهميت است (جدول ب). }
$$

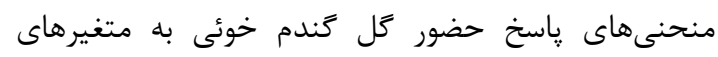

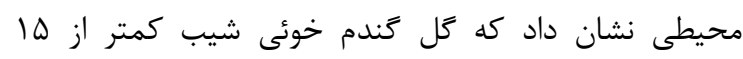

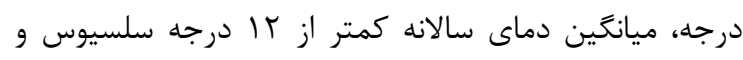

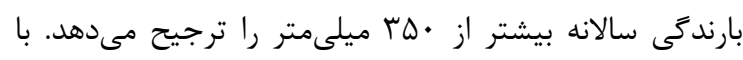

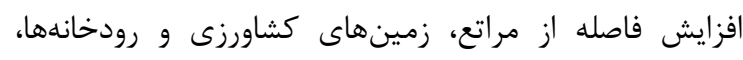

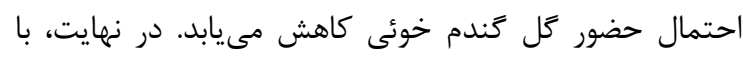

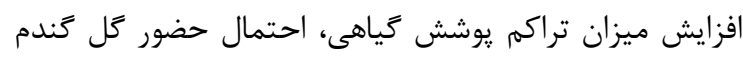
خوئى افزايش مى يابد (شكل سبر).

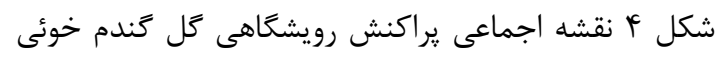

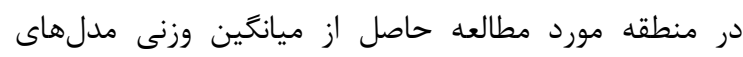



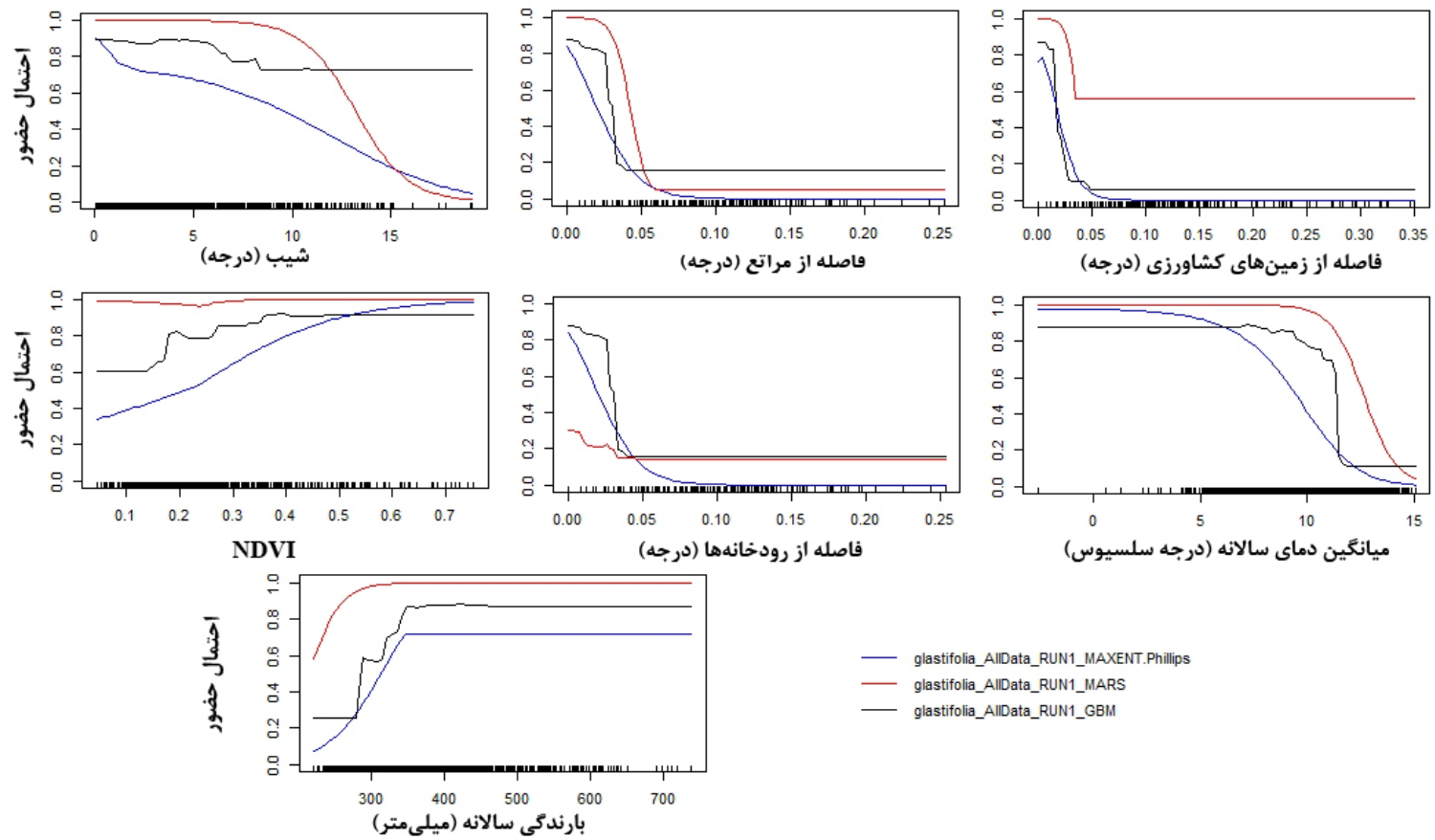

—_ glastifolia_AllData_RUN1_MAXENT.Phillips

_- glastifolia_AllData_RUN1_MARS

_ glastifolia_AIIData_RUN1_GBM

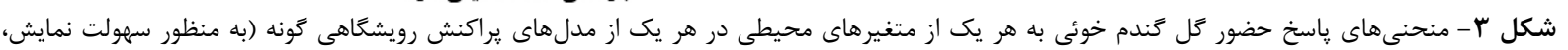

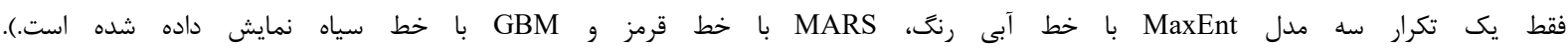

Figure 3. Response curves of Centaurea glastifolia presence to each environmental variable in each habitat distribution model (for better presentation, only one replication of three models; MaxEnt with blue line, MARS with red line and GBM with black line were presented.).

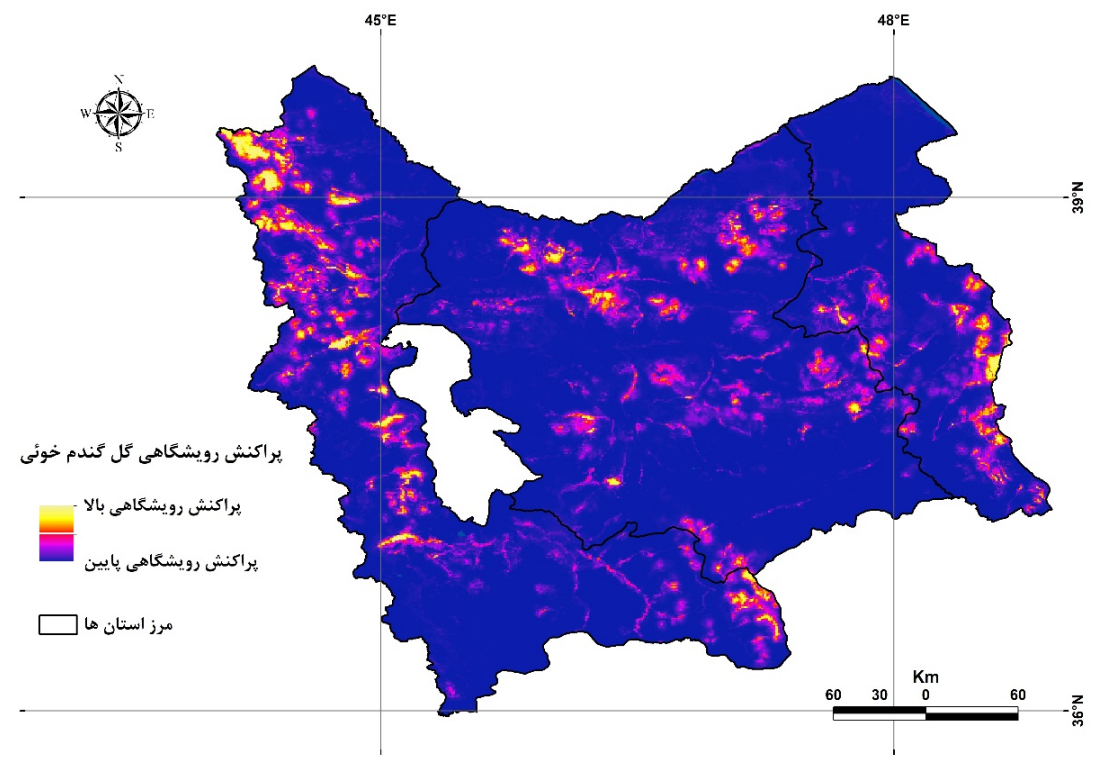

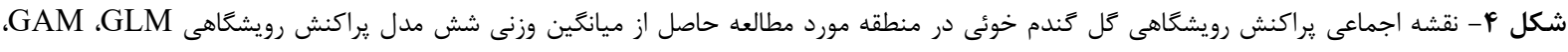

GBM g RF ،MaxEnt ،MARS

Figure 4. Ensemble habitat distribution map of Centaurea glastifolia in the study area result from mean-weighted of six habitat distribution model values i.e., GLM, GAM, MARS, MaxEnt, RF and GBM. 


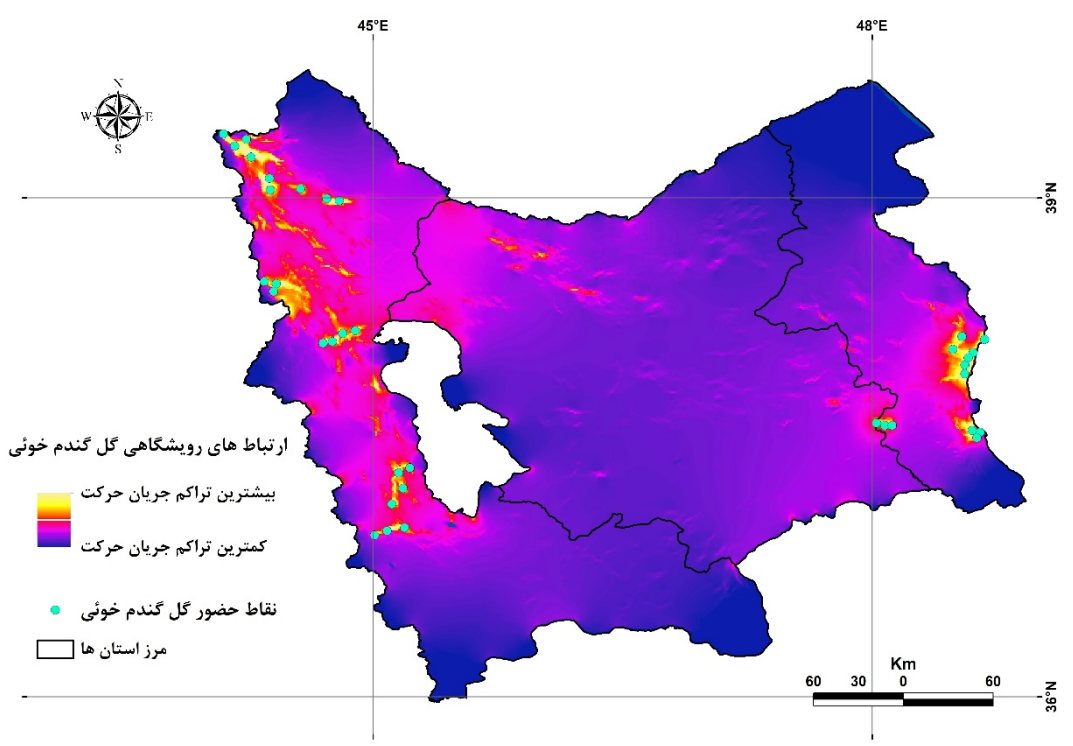

شكل ه- نقشه ارتباط رويشكاهى طراحى شده گونه كل گَندم خوئى در محدوده يراكنش آن در ايران بر اساس روش مدارهاى الكتريكى.

Figure 5. Designed habitat connectivity map of Centaurea glastifolia in its distribution area in Iran based on electricalcircuit method.

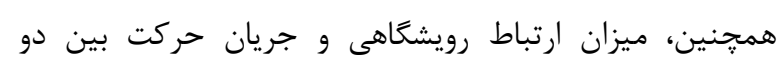

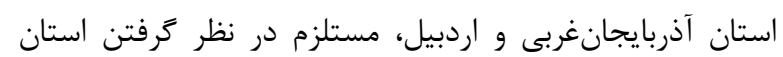
آذربايجانشرقى بود.

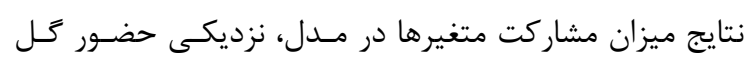

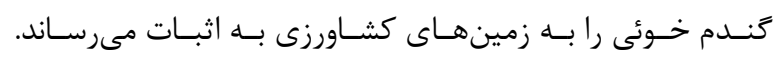

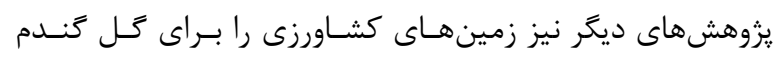

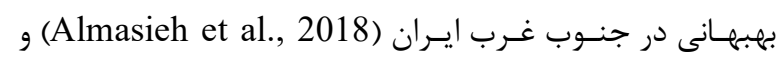

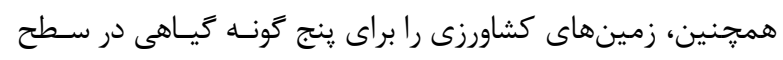

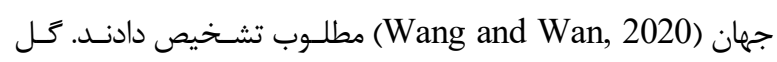

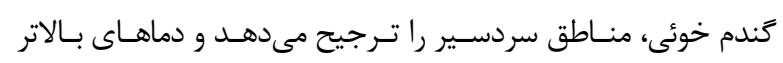

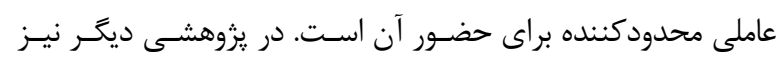

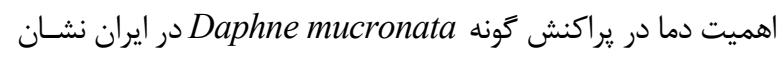

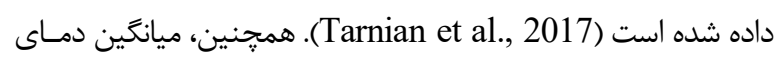

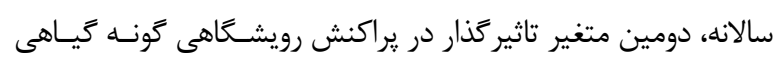
Bromus tomentellus

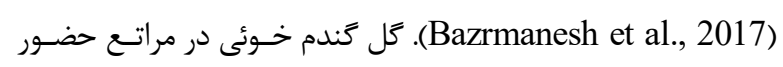

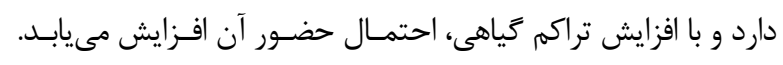

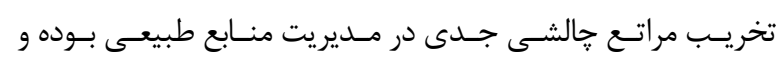

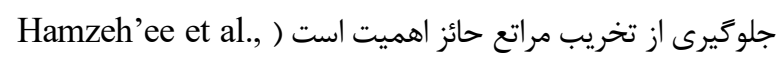

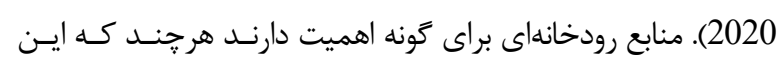

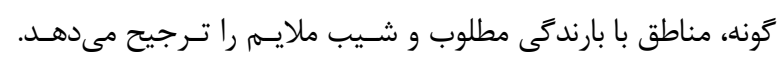

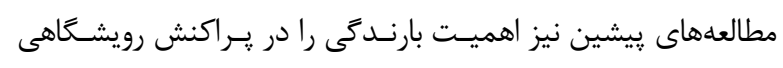

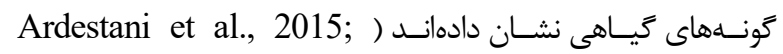

.(Tarnian et al., 2017; Almasieh et al., 2018
متغير خاك و يارامترهاى مربوط به آن نيز در اين مطالعه،

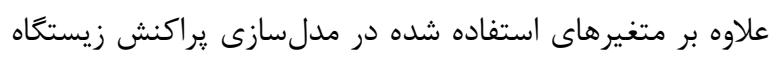

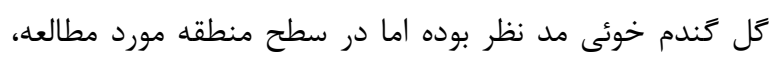

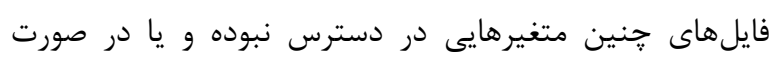

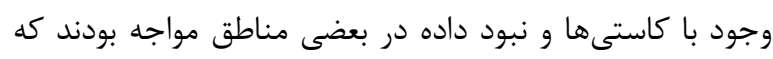

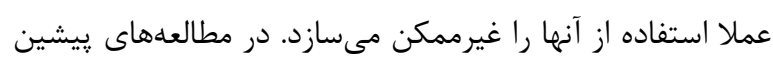

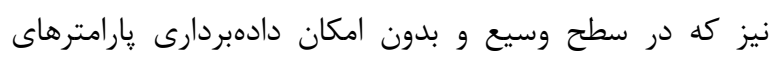

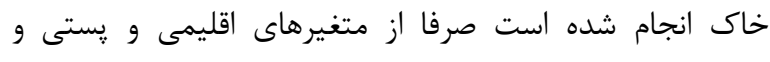

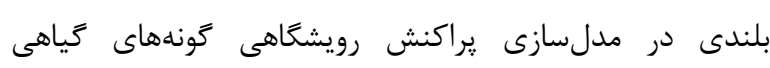

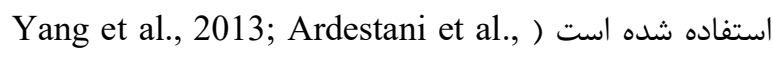
.(2015; Tarnian et al., 2017; Bazrmanesh et al., 2019 مدلسازى يراكنش رويشًاهى نشان داد كه مطلوبترين

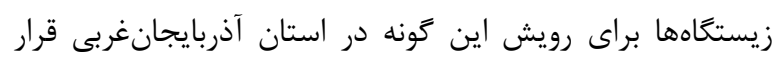

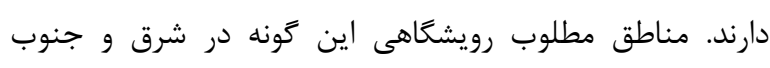

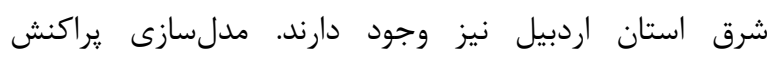

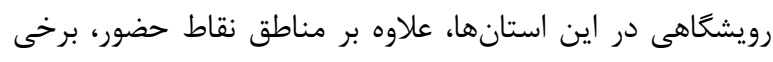

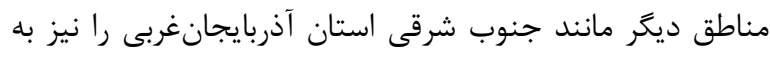

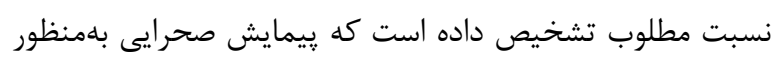

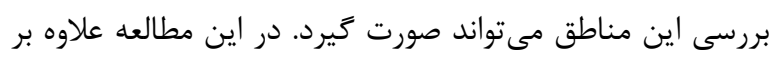

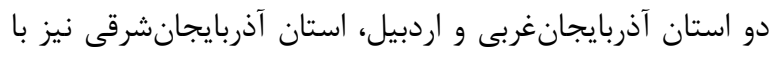

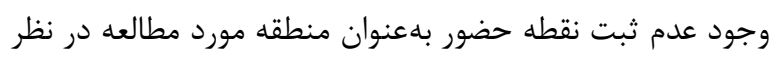

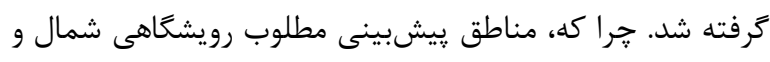

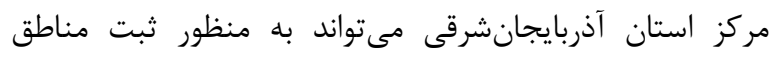

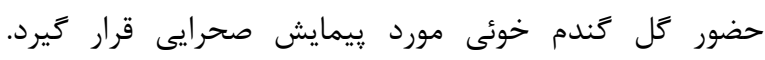




\section{REFERENCES}

Alavi, S.J., Ahmadi, K., Hosseini, S.M., Tabari, M. \& Nouri, Z. 2019. The response of English yew (Taxus baccata L.) to climate change in the Caspian Hyrcanian Mixed Forest ecoregion. Regional Environmental Change 19: 1495-1506.

Alignier, A., Ricci, B., Biju-Duval, L. \& Petit, S. 2013. Identifying the relevant spatial and temporal scales in plant species occurrence models: The case of arable weeds in landscape mosaic of crops. Ecological Complexity 15: 17-25.

Almasi, N., Karamian, R. \& Karimi, F. 2015. Antioxidant and antibacterial activity of the methanolic Centaurea L. species (Asteraceae) from Iran extracts of three. Journal of Plant Research 28: 224-234. (In Persian).

Almasieh, K., Zoratipour, A. Negaresh, K. \& DelfanHasanzadeh, K. 2018. Habitat quality modelling and effect of climate change on the distribution of Centaurea pabotii in Iran. Spanish Journal of Agricultural Research 16: e0304.

Altundağ, E. \& Gürdal, B. 2008. Anatomical characteristics of Centaurea glastifolia L. (Asteraceae) used as folk medicine in east Anatolia. Journal of Pharmacy of Istanbul University 40: 57-64.

Araújo, M.B. \& Guisan, A. 2006. Five (or so) challenges for species distribution modelling. Journal of Biogeography 33: 1677e1688.

Araújo, M.B. \& New, M. 2012. Ensemble forecasting of species distributions. Trends in Ecology \& Evolution 22: 42-47.

Araújo, M.B. \& Peterson, A.T. 2012. Uses and misuses of bioclimatic envelope modeling. Ecology 93: $1527 \mathrm{e} 1539$.

Ardestani, E.G., Tarkesh, M., Bassiri, M. \& Vahabi, M.R. 2015. Potential habitat modeling for reintroduction of three native plant species in central Iran. Journal of Arid Land 7: 381-390.

Bagheri, H., Ghorbani, A., Zare Chahouki, M.A., Jafari, A. \& Sefidi, K. 2019. Spatial distribution modelling of two species of Limonium iranicum and Aeluropus littoralis using regression logistic (case study: Kavir Mighan rangelands in Arak). Journal of Rangeland 13: 560-569. (In Persian).

Bazrmanesh, A., Tarkesh, M., Bashari, H. \& Poormanafi, S. 2019. Effect of climate change on the Ecological Niches of the climate of Bromus tomentellus Boiss using Maxent in Isfahan province. Journal of Range and Watershed Management 71: 857-867. (In Persian).

Blach-Overgaard, A., Svenning, J.C., Dransfield, J., Greve M. \& Balslev, H. 2010. Determinants of palm species distributions across Africa: the relative roles of climate, non-climatic environmental factors, and spatial constraints. Ecography (Cop.) 33: 380e391.

Borna, F., Tamartash, R., Tatian M.R. \& Gholami V. 2020. Predicting distribution habitat of Artemisia aucheri using Ecological Niche Factor Analysis (Case study: Summer Rangeland of Baladeh, Nour). Iranian Journal of Rangeland and Desert Research 27: 98-111. (In Persian).

Bremer, K. 1994. Asteraceae: Cladistics and Classification. Timber Press, Portland. 752 pp.
ارتباط رويشكاهى در يك منطقه ميتواند به انتشار و يراكنش

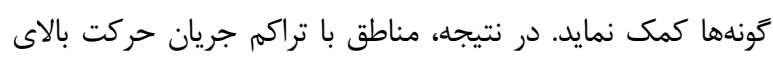

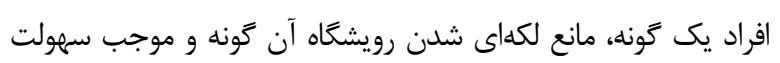

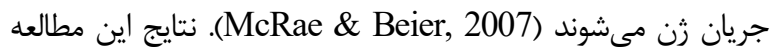

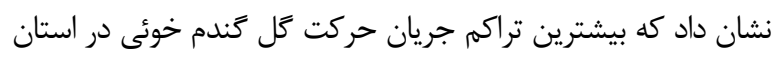

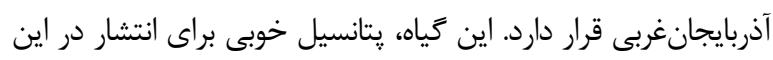

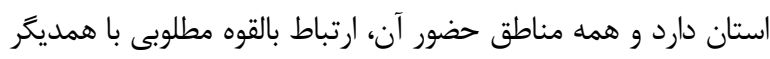

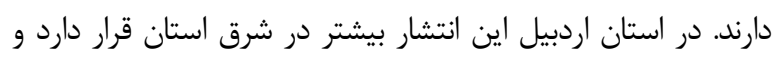

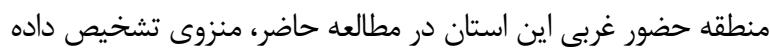

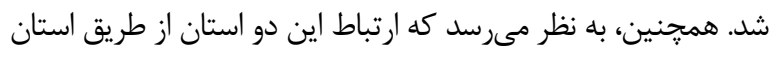

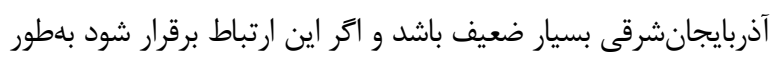

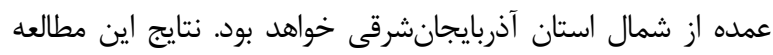

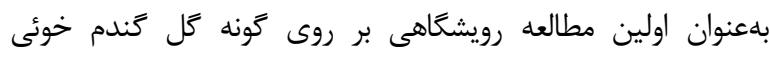

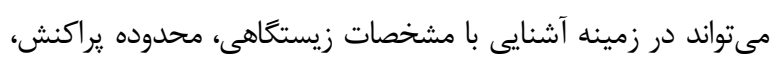
نحوه انتشار، جريان زن، يويايى جمعيت و دوام كَونه كمك نمايد.

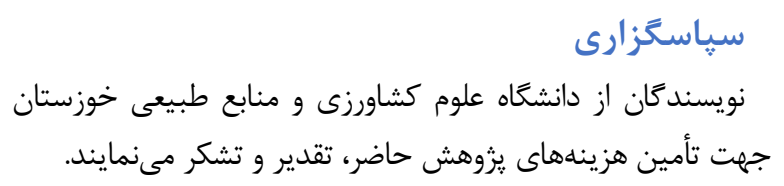


Brown, J.L. 2014. SDMtoolbox: a python-based GIS toolkit for landscape genetic, biogeographic, and species distribution model analyses. Methods in Ecology and Evolution 5: 694-700.

Crooks, K.R \& Sanjayan, M. 2006. Connectivity conservation. Cambridge, UK, Cambridge University Press. 730p.

Esfanjani, J., Zare Chahouki, M.A., Rouhani, H., Mohammad Esmaeli, M. \& Behmanesh, B. 2017. Suitability habitat modeling species using Ecological Niche Factor Analysis (ENFA) in rangelands Chaharbagh of Golestan province, Iran. Iranian Journal of Rangeland and Desert Research 23: 516526. (In Persian).

Eskildsen, A., Roux, P.C., Heikkinen, R.K., Høye, T.T., Kissling, W.D., Pöyry, J., Wisz, M.S. \& Luoto, M. 2013. Testing species distribution models across space and time: high latitude butterflies and recent warming. Global Ecology and Biogeography 22: 1293-1303.

Fick, S.E. \& Hijmans, R.J. 2017. Worldclim 2: New 1$\mathrm{km}$ spatial resolution climate surfaces for global land areas. International Journal of Climatology 37: 43024315. www.worldclim.org [accessed on 20 May 2019].

FRWMO (Forest, Range and Watershed Management Organization of Iran). 2010. Iranian Forests, Range and Watershed Management Organization National Land use/Land cover map.

Ghaedi, Z., Saberi-Pirooz, R., Ebrahimi, E., Badri. S. \& Ahmadzadeh, F. 2020. Genetic diversity within the Iranian spiny-tailed lizard and predicting species distribution in climate change conditions. Nova Biologica Reperta 7: 192-205. (In Persian).

Ghahremaninejad, F., Fereidounfar, S. \& Mozaffarian, V. 2012. Centaurea kabirkuhensis, a new name for Centaurea procera Mozaff. (Asteraceae). Annalen des Naturhistorischen Museums in Wien, Serie B 114: 133-134.

Guisan, A. \& Zimmermann, N.E. 2000. Predictive habitat distribution models in ecology. Ecological Modelling 135: 147-186.

Hamzeh'ee, B., Koshnevis M., Ashouri, P., Mozaffarian, V. \& Ravanbakhsh, H. 2020. The effect of fire on vegetation diversity indices, a case study: Sirachal research station. Nova Biologica Reperta 7: 92-105. (In Persian).

IRIMO (Islamic Republic of Iran Meteorological Organization). 2017. Climate data-base, Iranian cities, from 1993 to 2017.

Jafari, S.M., Zarre, S., Alavipanah, S.K. \& Ghahremaninejad, F. 2014. Exploring the generality of associations between plant functional traits: evidence within ecological groups along an altitudinal gradient in Hyrcanian forest. Plant Species Biology 29: e31-e39.

Jeffrey, C. 2007. Compositae, Introduction with key to tribes. In: Kadereit, J.W. \& Jeffrey, C. (eds.), The families and genera of vascular plants, Springer, Heidelberg, Germany, pp. 61-87.

Jueterbock, A. 2015. 'Maxent Variable Selection' vignette. $10 \mathrm{p}$.
Khalasai Ahvazi, L. \& Zare Chahouki, M.A. 2016. Preparing the distribution of Seidlitzia rosmarinus in Semnan East rangeland using ANN model. Iranian Journal of Rangeland and Desert Research 23: 275287. (In Persian).

McRae, B.H. 2006. Isolation by resistance. Evolution 60: 1551-1561.

McRae, B.H. \& Beier, P. 2007. Circuit theory predicts gene flow in plant and animal populations. Proceedings of the National Academy of Sciences USA, 104: 19885-19890.

McRae, B.H., Dickson, B.G. Keitt, T.H. \& Shah, V.B. 2008. Using Circuit theory to model connectivity in ecology, evoloution and conservation. Ecology 89: 2712-2724.

McRae, B.H. \& Shah, V.B. 2009. Circuitscape user's guide. The University of California, Santa Barbara, www.circuitscape.org [accessed on 20 April 2016]

Mozaffarian, V. 2018. Centaurea L. In: Assadi, M., Maassoumi, A.A. \& Safavi, S.R. (eds.), Flora of Iran 144: 262-391. Research Institute of Forests and Rangeland, Tehran. (In Persian).

Naimi, B., Hamm, N.A.S., Groen, T.A., Skidmore, A.K. \& Toxopeus, A.G. 2014. Where is positional uncertainty a problem for species distribution modelling? Ecography 37: 191-203.

Negaresh, K. 2019. Centaurea khosraviana (Asteraceae, Cardueae), a new species from NW Iran. Annales Botanici Fennici 56: 115-122.

Öksüz, S. \& Topcu, G. 1994. Guaianolides from Centaurea glastifolia. Phytochemistry 37: 487-490.

Pearson, R.G., Thuiller, W., Araújo, M.B., Martinez-Meyer, E., Brotons, L., McClean, C., Miles, L., Segurado, P., Dawson, T.P. \& Lees, D.C. 2006. Model-based uncertainty in species range prediction. Journal of Biogeography 33: 1704-1711.

Piri Sahragard, H., Zare Chahuoki, M.A. \& Azarnivand, H. 2016. Developing predictive distribution map of plant species habitats using logistic regression (Case study: Khalajestan rangelands of Qum province). Journal of Rangeland, 9: 222-233. (In Persian).

Piri Sahragard, H., Ajorlo, M. \& Karami, P. 2018. Modeling habitat suitability of range plant species using random forest method in arid mountainous rangelands. Journal of Mountain Science 15: 21592171.

R Development Core Team. 2018. R: A language and environment for statistical computing. Vienna, Austria: R Foundation for Statistical Computing, https://www.R-project.org [accessed on 10 May 2019].

Roever, C.L., van Aarde, R.J. \& Leggett, K. 2013. Functional connectivity within conservation networks: Delineating corridors for African elephants. Biological Conservation 157: 128-135.

Shahnaseri G., Hemami, M-R., Khosravi, R., Malakoutikhah, S., Omidi, M. \& Cushman, S.A. 2019. Contrasting use of habitat, landscape elements, and corridors by grey wolf and golden jackal in central Iran. Landscape Ecology 34:1263-1277.

Sirami, C., Caplat, P., Popy, S., Clamens, A., Arlettaz, 
R., Jiguet, F., Brotons, L. \& Martin, J.-L. 2016. Impacts of global change on species distributions: obstacles and solutions to integrate climate and land use. Global Ecology and Biogeography 26: 385-394.

Sousa-Silva, R., Alves, P., Honrado, J. \& Lomba, A. 2014. Improving the assessment and reporting on rare and endangered species through species distribution models. Global Ecology and Conservation 2: 226237.

Tarnian, F., Azarnivand, H., Yazdanparast, R., Zare Chahouki, M.A., Jafari, M., \& Kumar, S. 2017. Identifying potential habitats and influencing variables on Daphne mucronata Royle distribution. Journal of Rangeland 11: 179-192. (In Persian).

Thuiller, W., Lafourcade, B. Engler, R. \& Araújo, M.B. 2009. BIOMOD-A platform for ensemble forecasting of species distributions. Ecography 32: 369-373.

Thuiller, W., Georges, D., Engler, R. \& Breiner, F. 2016. Biomod2: ensemble platform for species distribution modeling. $\mathrm{R}$ package version 3.4.6. http://CRAN.R-project.org/package/biomod2 [accessed on 10 March 2020].

Urban, D.L., Minor, E.S., Treml, E.A. \& Schick, R.S. 2009. Graph models of habitat mosaics. Ecology Letters 12: 260-273.

van Proosdij, A.S.J., Sosef, M.S.M., Wieringa, J.J. \& Raes, N. 2016. Minimum required number of specimen records to develop accurate species distribution models. Ecography 39: 542-552.

Wagenitz, G. 1980. Centaurea L. In: Rechinger, K.H. (ed.), Flora Iranica, 139b: 313-420, Akademische Druck-und, Verlagsanstalt, Graz.

Wagenitz, G. 1983. Centaurea and Index Kewensis. Taxon 32: 107-109.

Wagenitz, G. \& Hellwig, F.H. 1996. Evolution of characters and phylogeny of the Centaureinae. In:
Hind, D.J.N. \& Beentje H.G. (eds.), Compositae: Systematics Proceedings of the International Compositae Conference, Royal Botanic Gardens, Kew, pp. 491-510.

Wan, H.Y., Cushman, S.A. \& Ganey, J.L. 2019. Improving habitat and connectivity model predictions with multi-scale resource selection functions from two geographic areas. Landscape Ecology 34: 503-519.

Wang, C.J \& Wan, J.Z. 2020. Assessing the habitat suitability of 10 serious weed species in global croplands. Global Ecology and Conservation 23: e01142.

Yang, X.Q., Kushwaha, S.P.S., Saran, S., Xu, J. \& Roy. P.S. 2013. Maxent modeling for predicting the potential distribution of medicinal plant, Justicia adhatoda L. in Lesser Himalayan foothills. Ecological Engineering 51: 83-87.

Zare Chahuoki, M.A., Abbasi, M. \& Azarnivand, H. 2014. Evaluating the ability of artificial neural network model in predicting the spatial distribution of plant species (case study: rangeland of Taleghan miany). Journal of Rangeland, 8: 106-114. (In Persian).

Zare Chahouki, M.A., Abbasi M. \& Azarnivand, H. 2018. Prediction of potential habitat for stipa barbata species using maximum entropy model (case Study: Taleghan Miany Rangelands). Journal of Rangeland 12: 35-46. (In Persian).

Zare Chahouki, M.A. \& Abbasi, A. 2018. Habitat prediction model medicinal species of Rheum ribes $\mathrm{L}$. with Maximum Entropy model in Chahtorsh rangeland of the Yazd province. Journal of Range and Watershed Management 71: 379-391. (In Persian).

Zuur, A.F., Ieno, E.N. \& Elphick, C.S. 2010. A protocol for data exploration to avoid common statistical problems. Methods in Ecology and Evolution 1: 3-14.

How to cite this article:

Almasieh, K., Negaresh, K., \& Mahmoodi, M. 2021. Habitat distribution and connectivity modelling of Centaurea glastifolia in northwest of Iran. Nova Biologica Reperta 8: 142-153. (In Persian).

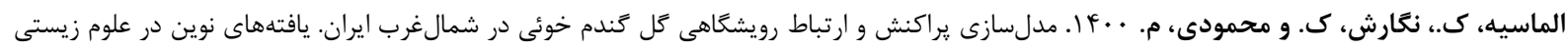

